\title{
Census of marine migration launched to gauge fish stocks
}

Rex Dalton, San Diego

Are there plenty more fish in the sea? The question continues to reverberate around most of the world's fishing grounds, but scientific data on the subject can sometimes prove elusive.

That's why researchers whose interests include species conservation and oceanography, as well as fisheries management, are keen to get more reliable information on the movements of marine animals. This month, on the Pacific seaboard of the United States, marine biologists took a big step towards their goal of understanding these migrations.

Researchers returned to San Diego from the ocean on 17 August after snagging and electronically tagging 80 tuna as part of the Tagging of Pacific Pelagics (TOPP) project, which aims to track bluefin tuna, several types of shark and albatross, elephant seals, leatherback sea turtles and other freeranging species.

TOPP is part of an ambitious global undertaking called the Census of Marine Life, funded by the New York-based Alfred P. Sloan Foundation, the US Office of Naval Research and several other agencies. The census is intended to chart the diversity, abundance and distribution of marine organisms in the world's oceans over the next decade.

"The tagging will create a data set by observing animals that will present a better picture of the ocean," says Jesse Ausubel, an environmental scientist at Rockefeller University in New York who coordinates the Sloan Foundation's funding of TOPP, which involves 60 biologists, oceanographers and computer scientists.

The tagging project is the first of about a dozen similar schemes around the world that will be carried out as part of the marine census, and exploits the latest technological advances in tagging devices that can be attached to animals. Its tags store data on species location, water temperature and depth. The project uses both archival tags, which are recovered when species are caught or found dead, and transmitting ones - some as small as a deck of cards that send information regularly for analysis via a French satellite instrument called ARGOS.

Barbara Block, a marine biologist at Stanford University in California who has pioneered tuna-tagging projects in the Atlantic Ocean (see Science 293, 1310-1314; 2001), is leading TOPP in the Pacific. "The fishing was so good we ran out of electronic tags," she says of this month's voyage.

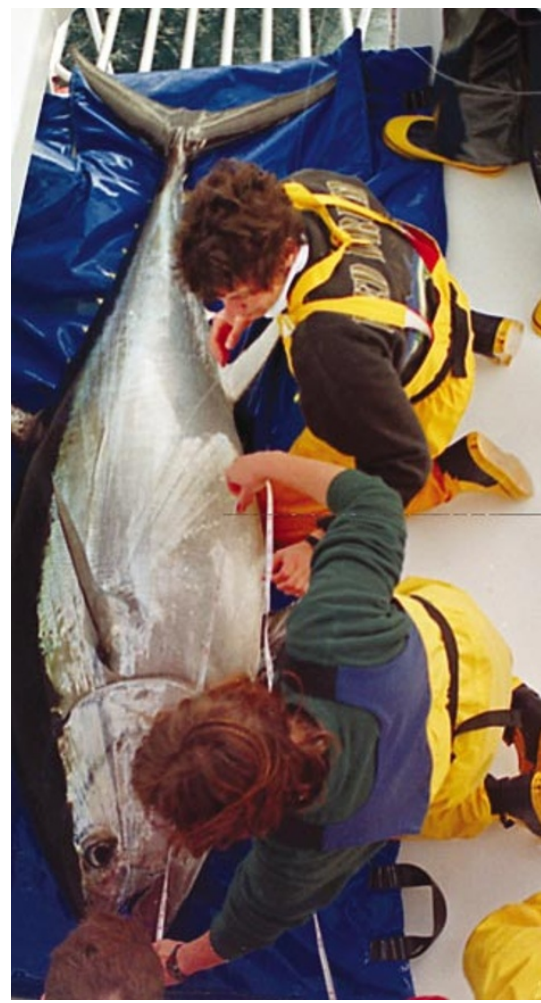

Size matters: measuring and tracking tuna helps researchers assess the status of fish populations.

TOPP's participants have also launched tagging operations to track salmon sharks off Alaska, blue sharks off Los Angeles, humpback whales off Oregon, and albatross near Hawaii and the Galapagos Islands.

George Boehlert, director of Oregon State University's marine laboratory in Newport, who studies the physical environments in which marine species live, says that data obtained from the tagging will help researchers to understand why animals venture to certain oceanic regions.

The information will complement that obtained from several other exploratory systems. For example, elephant seals, which plunge to depths of more than 600 metres several times an hour when at sea, will be monitored by the Argo float system that is being deployed to chart deep ocean currents and their impact on climate (see Nature 415, 954-955;2002).

Researchers hope that the tagging of tuna and other species will reveal migratory routes that will help biologists to understand Pacific fisheries. The project brings together groups of researchers from fields that do not traditionally interact. "Everyone is now on the same playing field," says Block.

www.toppcensus.org
Controversial animal feed builds concrete career in construction

\section{David Adam, London}

Walls have ears, and soon they could have the burnt remains of snouts, bones and skin as well. No longer able to feed meatand-bone meal (MBM) to farm animals, British researchers are assessing its potential as a construction material.

The Meat and Livestock Commission has asked engineers at the Building Research Establishment (BRE) in Watford, near London, to investigate whether ash from incinerated MBM can be mixed into concrete and used to fill holes, lay roads and even build houses.

About 2.5 million tonnes of MBM are produced in Europe each year as a byproduct of the meat trade. MBM was used in animal feed in Britain until 1996, when the practice was banned because the feed was thought to be playing a role in the spread of mad-cow disease.

Slaughterhouses are now left with mountains of animal leftovers that they currently incinerate and pay to dump as landfill.

The industry is keen to find cheaper ways to dispose of this unwanted legacy. One option is to use the MBM ash as an alternative 'aggregate' - material such as crushed stone and gravel that is used to make concrete. Ash from domestic incinerators is already used to make concrete in some European countries.

"The construction industry could basically have the stuff for free if it helped to offset disposal costs," says Martin Grantley-Smith, head of planning at the Meat and Livestock Commission in Milton Keynes.

Next month, a BRE team will start testing the mechanical strength of concrete made with the animal ash, and will see if any substances leach out. Ash has a different density and chemical composition depending on the burnt material.

"MBM ash contains a lot of calcium phosphate, not surprisingly because that's what bones are made of," says Rod Collins, who heads the BRE team. He adds that the MBM ash could possibly be used in construction, but acknowledges that people might not accept materials containing MBM in housing.

Collins is confident that the infectious agent that may cause mad-cow disease will not be a problem, however, as it should be destroyed in the incinerator. "You can never be absolutely certain," he admits. "But we're as sure as we can be that the material would be safe." 